\title{
Do males pay more? A male-biased predation of common lizard (Zootoca vivipara) by great grey shrike (Lanius excubitor)
}

\author{
Marcin Antczak ${ }^{1} \cdot$ Anna Ekner-Grzyb ${ }^{1} \cdot$ Igor Majláth $^{2}$ • Viktoria Majláthová ${ }^{2,3} \cdot$ Martin Bona $^{4} \cdot$ Martin Hromada ${ }^{5,6}$. \\ Piotr Tryjanowski ${ }^{7}$
}

Received: 25 April 2018 / Revised: 15 April 2019 / Accepted: 7 May 2019/Published online: 11 June 2019

(C) The Author(s) 2019

\begin{abstract}
Predation is one of the most important factors affecting biology, ecology and behaviour of the prey. We have studied predation of the common lizard (Zootoca vivipara) by the great grey shrike (Lanius excubitor) in farmland habitats in western Poland. Shrike caches were used as a source of information about preyed lizards. Shrikes hunt significantly more adult males than females, juveniles and sub-adults; the pattern was similar over all three study years. Male lizard had longer activity time than female; therefore, they seem to be under predation pressure for a longer time during breeding season. Capture and count transect data of common lizard populations living within and outside shrike territories showed significant seasonal differences: within shrike territories, there was lower proportion of males than females; moreover, in some territories, the number of males in the lizard population was negatively correlated with the number of males impaled by shrikes. Our findings suggest that in this particular predator-prey system, shrikes may be a strong selective force for lizards' population dynamics. Male-biased predation could be caused by differences in the behaviour of adult male and female lizards, namely longer activity of males and differences in space and refuge use.
\end{abstract}

Keywords Bird $\cdot$ Impaling behaviour $\cdot$ Laniidae $\cdot$ Reptile $\cdot$ Sex ratio $\cdot$ Predator-prey interaction

Anna Ekner-Grzyb

aekner@amu.edu.pl

1 Department of Behavioural Ecology, Adam Mickiewicz University, 61-614 Poznań, Poland

2 Institute of Biology and Ecology, Faculty of Science, University of P.J. Šafárik, 04001 Košice, Slovakia

3 Institute of Parasitology Slovak Academy of Sciences, 040 01 Košice, Slovakia

4 Department of Medical Physiology, Faculty of Medicine, University of P.J. Šafárik, 04180 Košice, Slovakia

5 Laboratory and Museum of Evolutionary Ecology, Department of Ecology, Faculty of Humanities and Natural Sciences, University of Presov, 08116 Prešov, Slovakia

6 Faculty of Biological Sciences, University of Zielona Góra, Szafrana 1, 65-516 Zielona Góra, Poland

7 Institute of Zoology, Poznań University of Life Sciences, 60-625 Poznań, Poland

\section{Introduction}

Predation is a common pressure experienced by animals in the wild and broadly accepted as one of the most powerful evolutionary forces shaping prey life history traits and behaviour (Lima and Dill 1990). Predators rarely hunt in a random manner; some categories of prey are exploited more frequently than others (Hayward et al. 2014; Grange et al. 2015; Marescot et al. 2015). The risk of being depredated might vary according to sex and size classes, body size, colour morphs, cognitive skills or predators faced (Gabor and Page 2003; Moyaho et al. 2004; Stapley 2004; Thaker et al. 2009; Surmacki et al. 2013; Marshall et al. 2015). Selective predation is believed to impact life history traits, sexual selection, several demographic characteristics of prey populations or behaviour (Carvalho and Del-Claro 2004; Campos et al. 2009; Ekner-Grzyb et al. 2013; Hoy et al. 2015; Sheriff et al. 2015; Gazzola et al. 2017; Pruitt et al. 2017). The prey-predator interaction may be direct and lethal, as well as non-lethal, mainly mediated by fear (Lima 1998; Gallagher et al. 2016; Gazzola et al. 2017). 
Lizards are popular models in studies of predator-prey interactions (Padilla et al. 2005; Hawlena and Perez-Mellado 2009; Cogălniceanu et al. 2015; Bateman et al. 2017; Pellitteri-Rosa et al. 2017; Constanzo-Chávez et al. 2018). The research concentrated mostly on the influence of predation risk on life history traits and behaviour, as well as predation avoidance (Cooper and Vitt 1991; Hawlena et al. 2010; Majláth and Majlathova 2009; Padilla and Nogales 2009; York and Baird 2016). For example, studies on lizards have shown that utilisation of refugees (Martin 2001; Stapley 2004; Cooper 2006a, 2006b; Cooper 2007; Cooper and Whiting 2007; Majláth and Majlathova 2009), several morphology traits including size and colouration (Stamps 1984; Cooper and Vitt 1991; Cabido et al. 2009), habitat use and escape behaviour (Martin and López 1995; Cooper 2007) are primarily modified by the presence of predators.

Although birds are widely recognised as important lizard predators (Martín and López 1990, 1996; Manganaro et al. 1999; Bloomberg and Shine 2000), the importance of avian predation on many aspects of lizard populations is largely unknown (e.g. Steen et al. 2011). Some species and/or populations of lizards might experience selective predation pressure from avian predators. Costantini et al. (2007) describe sex-biased predation in which the Euroasian kestrels (Falco tinnunculus) preyed mainly on males of the western green lizard (Lacerta bilineata). For predatory birds, the size of lizards seems to be an important characteristic of potential prey. A size-biased predation pattern (e.g. size selection toward larger specimens of Anolis lizards) has been detected in the American kestrel (Falco sparverius; McLaughlin and Roughgarden 1989). The reverse relationship was found in kookaburra (Dacelo novaeguineae) feeding on the highland water skink (Eulamprus tympanum), where small classes of prey were taken more frequently than larger ones (Bloomberg and Shine 2000). Similarly, in case of a skink (Eumeces okadae) predated by thrush (Turdus celaenops), smaller juveniles were taken more frequently than larger adults (Hasegawa 1990). However, in insular environments, where lizards compose an important part of the diet of birds, avian predators prefer larger individuals (Padilla et al. 2007; Padilla et al. 2009). Interestingly, Hawlena et al. (2010) recorded that anthropogenic changes were profitable for the southern grey shrike (Lanius meridionalis) altered predation risk on desert lizard populations.

In this paper, we focused on great grey shrike (Lanius excubitor). True shrikes of family Laniidae are small- to medium-sized passerines similar in behaviour and feeding habits to raptors (Lefranc and Norfolk 1997, Hromada et al. 2003, 2008, Antczak et al. 2005a, Yosef et al. 2018). In order to hunt a prey, shrikes sit high above a ground, e.g. top branch, high sticks or electrical power line or hover for a whilst and scan the surrounding ground and air. Shrikes are known to be very opportunistic and flexible predators in their use of different food spectra as well as in hunting tactics; they can kill and consume small vertebrates, including lizards, which are regarded as important components of the shrike's diet (Lepley et al. 2004; Antczak et al. 2005a; Padilla et al. 2005; more general information Lefranc and Norfolk 1997). One of the extraordinary behaviours displayed by shrikes is impaling prey items on sharp objects such as perches, thorns and barbed wire. This behaviour serves several functions. Shrikes, in contrast to raptors, do not have talons or strong feet; therefore, impaling of prey is necessary for dismembering and portioning larger prey items. Besides, it offers opportunities to access otherwise toxic prey (Antczak et al. 2005b). Moreover, impaling behaviour has a signalling function (Antczak et al. 2005a). Impaled prey might be a source of information about territory occupation or/and prey quality (Yosef and Pinshow 1989; Morelli et al. 2015; Hromada et al. 2008, for a review see Yosef and Pinshow 2005,).

The conspicuousness of food remains and food caches (i.e. the observation of fresh-kills that are complete or even still alive) means that shrike caches provide a unique source of information about the characteristics of taken prey (e.g. size, sex, morphology, ectoparasites). This improves upon traditional methods of diet analyses (e.g. pellets, neck collars, retrigulated food, stomach contents) in which a large part of such data is absent (Hromada et al. 2003).

The great grey shrike represents one of largest true shrike species with a very variable diet consisting mainly of insects and small vertebrates, including lizards, which are regularly hunted and impaled (Lefranc and Norfolk 1997; Antczak et al. 2005a). In this paper, we present data on predation of the great grey shrike on the common lizard (Zootoca vivipara). We focus on differences in predation vulnerability between sexes and adulthood in the common lizard. We test the influence of predation on the sex ratio in lizard populations by comparing common lizard populations living under presence and absence of predator the great grey shrike. We hypothesise that great grey shrikes may change the abundance of the common lizard living in the same territories.

\section{Methods}

\section{Study area}

The study was carried out near the town of Odolanów $\left(51^{\circ} 34^{\prime}\right.$ $\mathrm{N}, 17^{\circ} 40^{\prime} \mathrm{E}$ ) in western Poland during the three consecutive pre-breeding and breeding seasons of the great grey shrike (January-end of May, from 2006 to 2008). The study area $\left(220 \mathrm{~km}^{2}\right)$ is an agricultural landscape with arable fields, meadows, pastures, fellow land patches and small woodlots of different ages, which are in some cases connected by rows of trees. This area supports one of the densest populations of the great grey shrike in western Poland and Europe 
(Tryjanowaki et al. 1999; Antczak et al. 2004). Two species of lizard are found in this region, the common lizard and the sand lizard (Lacerta agilis); both occur at high densities (Ekner et al. 2008). However, among the impaled reptiles, the presence of the sand lizard was marginal $(<2 \%$ of all predated lizards); therefore, it was ignored in the study.

\section{Prey data}

The population of the great grey shrike has been under detailed study since 1998, so we have detailed knowledge about the distribution of this bird on the study plot. Each year, intensive surveys for territories, breeding pairs and nests are conducted starting in mid-February. We also monitor the presence of shrikes in the winter months, including searches for impaled prey. To collect data about preyed lizards, searching sessions for impaled prey throughout the territories were performed from January to end of May. Great grey shrikes also hunt for lizards in June and July; however, at this time, nestlings leave the nests and families disperse over territories and preyed lizards are transported directly to nestlings. As a consequence, we restrict our analyses to the pre-breeding and nestling periods and ended in last days of May. Impaling behaviour of the studied shrike population shows some specific spatio-temporal changes described in a former study (Antczak et al. 2005a) and we have long-term experience in the study of food-caching behaviour of shrikes (Antczak et al. 2005a).

In order to find shrike larders, we carefully looked for the prey, observing in detail all of the branches, thorns and other impaling places in each territory. The prey were searched at all heights (using binoculars); however, larders were usually found at about 50-200 $\mathrm{cm}$ above the ground. For impaled lizards, the following data were collected: date, species of lizard, sex, adulthood, snout to vent length (SLV), presence of autotomy and state of prey (alive, fresh, dry). Because of variable preservation (e.g. partial consumption of preyed lizards, dry state of prey), sample sizes differ between analyses. The sample sizes of impaled lizards were similar in all years of the study (2006 - 50, 2007-41,2008-65) and we surveyed similar numbers of shrikes' breeding territories throughout the study periods (2006-12, 2007-10, 2008-19), with mean number of impaled lizard specimens per territory: $3.78 \pm 4.10$ (range 1-19).

\section{Lizard data}

To test the influence of the great grey shrike predation on the sex ratio and adulthood of common lizard populations, we compared lizard populations living within shrike territories and control sites. Selected control sites have to fulfil the following criteria: no presence of the great grey shrike over past breeding seasons, minimum distance from the borders of active shrike territories $500 \mathrm{~m}$ and the habitat composition similar to shrike territories. We used two sources of data about the lizard populations: transect routes and capture data.

Common lizards were counted on 200-m transects selected at random over shrike territories and control sites. At each territory, shrikes were present at least from 3 years before and that shrike individuals stable impaled prey (Antczak et al. 2005a, b), and at additionally controlled site, three transects were surveyed. During transect counts, a qualified observer walked slowly, noting down all visible lizards whilst trying to determine species, sex and size classes of observed individuals. All counts were performed during weather conditions optimal for maximum activity of lizards (10:00 to 16:00). Lizards were counted and captured in 8-24 May 2006 and 23 April-2 May 2007; difference in the timing of record data was related to difference in weather conditions between years, and because problem with rain were impossible to collect data in similar transect efficiency in 2008 (Ekner et al. 2008).

Additionally, to establish demography of common lizard population, animals were captured using landing fishnets or by hand. Animals were sexed and determined in terms of a given size classes (adulthood; adult, sub-adult, juvenile) according to reference and our previous field experience, based on molecular and capture-recapture data (Ekner et al. 2008, 2011). The size classes were defined by size and colour. Juvenile individuals are much more darker than sub-adults and adults; they have dark brown or black skin (Juszczyk 1987). The differences between sexes were defined mainly by two traits: swelling at the base of the male's tail where the copulatory organ exists (hemipenes) and stage development of the femoral pores.

\section{Data processing}

All basic statistics were done according to Zar (1999). The sex ratio in impaled lizards was compared using a chi-square test. In order to avoid using the same territories and control sites more than once, we tested sex ratio independently for 2006 and 2007. The sex ratio in control and populations within shrike territories was compared using the Fisher exact test. To avoid pseudoreplication in the case of multiple territory entries, GLM main effect ANOVA was applied to test for the influence of territory as random factor, and year and sex as fixed factors. In order to test particular size and sex, classes biased shrikes' predation, $D$, selectivity index (Jacobs 1974), calculated as $D=(r-p) /(r+p-2 r p)$ in which $r=$ size classes and sex classes ratio in the food and $p=$ size and sex classes ratio in the environment was used. Confidential limits to $D$ index was calculated according to Strauss (1979). The $D$ index can take values from -1 (total avoidance) to +1 (total preference). Values close to zero (from -0.1 to +0.1 ) indicate a lack of relationship. Calculations of $D$ index were performed for 2006 (three 
territories) and 2007 (seven territories) years separately, and to avoid pseudoreplication, we used each territory only once. Moreover, to avoid seasonal bias in the calculations, we included data from prey searches close to the time when the capture sessions were done. In total, for $D$ index of selectivity calculations, data about 51 preyed lizards and 55 lizards captured during capture sessions were used.

\section{Results}

\section{Predated lizards}

Over the 3-year study period, a total of 153 impaled common lizards were found (Fig. 1). Among impaled individuals, the majority were classified as adults $(130,84.9 \%)$, whereas juveniles and sub-adults comprised $15.1 \%$ (15 and 8 individuals respectively) of whole number of recorded prey $\left(\chi^{2}=73.43\right.$, $P<0.0001)$. Considering adult common lizards, males $(n=$ $109,66.6 \%$ ) were preyed upon significantly more frequently than females $\left(21, \chi^{2}=32.13, P<0.0001\right)$.

GLM main effect ANOVA showed the following results (intercept: $\mathrm{SS}=51.83, \mathrm{df}=1, \mathrm{MS}=51.83, F=8.65, P=$ 0.005; Table 1). Male-biased predation was not affected by territory or year of study $(\mathrm{SS}=119.43, \mathrm{df}=25, \mathrm{MS}=4.77$, $F=0.64, P=0.83 ; \mathrm{SS}=8.10, \mathrm{df}=2, \mathrm{MS}=4.05, F=0.55$, $P=0.58$; respectively). Thus, the higher predation risk experienced by males of the common lizard was not influenced by the hunting of individual shrikes. However, there was a significant difference between the number of males and females among impaled individuals $(\mathrm{SS}=41.72, \mathrm{df}=1, \mathrm{MS}=41.72$,

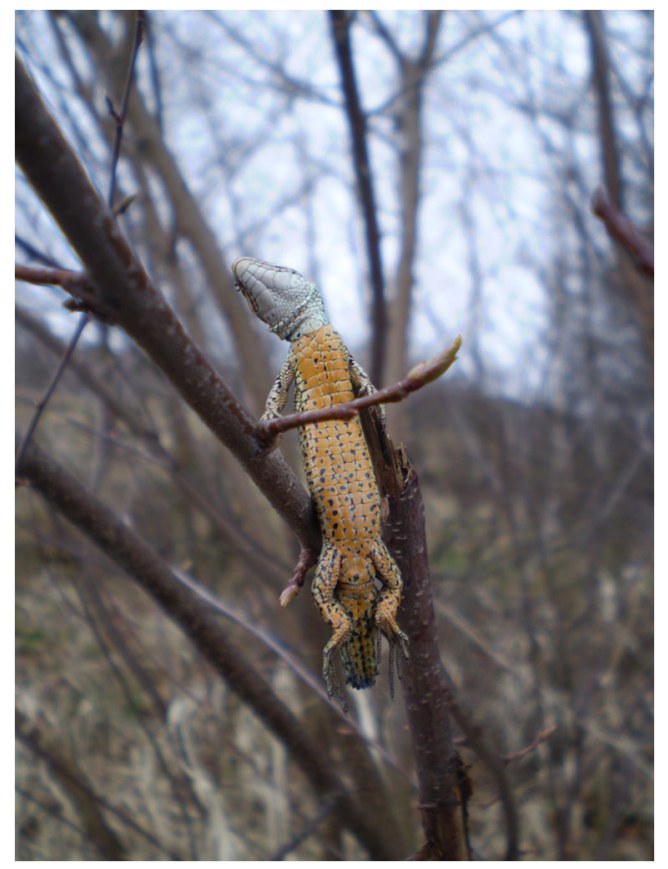

Fig. 1 Fresh impaled adult common lizards, L. vivipara
Table 1 GLM results of main effects ANOVA as depended variable number of impaled lizards was used, territory was used as random variable, year and sex were used as fixed factors (significant results are in italics)

\begin{tabular}{lrrrll}
\hline Effect & \multicolumn{1}{c}{ SS } & df & \multicolumn{1}{l}{ MS } & $F$ & $P$ \\
\hline Intercept & 51.83 & 1 & 51.83 & 8.65 & 0.005 \\
Territory & 119.43 & 25 & 4.77 & 0.64 & 0.83 \\
Year & 8.10 & 2 & 4.05 & 0.55 & 0.58 \\
Sex & 41.72 & 1 & 41.72 & 5.72 & 0.027 \\
\hline
\end{tabular}

$F=5.72, P=0.027)$. The dominance of males among preyed lizards by the great grey shrike was recorded in all three study seasons, as well as during all months of the study.

All interactions were non-significant and are not mentioned in the results.

Because lizards were counted and captured by researchers only in two breeding seasons, great grey shrike selection toward particular sex and size classes determined by $D$ index were calculated for 2006 and 2007 (males 0.654, females 0.440 , sub-adults -0.321 , juveniles -0.287 ; , males 0.863 , females -0.554 , sub-adults -0.877 , juveniles -0.135 ; respectively). Obtained results showed that shrikes caught more males than females as well as sub-adults and juveniles of common lizard (Table 2).

\section{Seasonal pattern in predation}

During study period, first impaled common lizards were recorded extremely early in warm January 2007, but the largest numbers were recorded in March and April with a clear peak in April (Fig. 2) and slight drop in May. Males were recorded significantly earlier in shrike caches than females in the same shrike territories (Wilcoxon matched pair test, $Z=2.02, p=$ $0.04, N=6)$.

\section{Sex ratio of common lizard populations}

Because of the structure of our data, the sex ratio comparisons were done independently for 2006 and 2007, as well as for used method. In the case of capture data, in 2006, the

Table 2 Preferences of great grey shrike toward particular sex and size classes determined by $D$ index (calculations were done for 2006 and 2007 separately, numbers in parenthesis denote number of breeding territories studied in given year)

\begin{tabular}{lcc}
\hline Sex adulthood & Year 2006 (3) & Year 2007 (7) \\
\hline Males & 0.654 & 0.863 \\
Females & -0.440 & -0.554 \\
Sub-adults & -0.321 & -0.877 \\
Juveniles & -0.287 & -0.135 \\
\hline
\end{tabular}




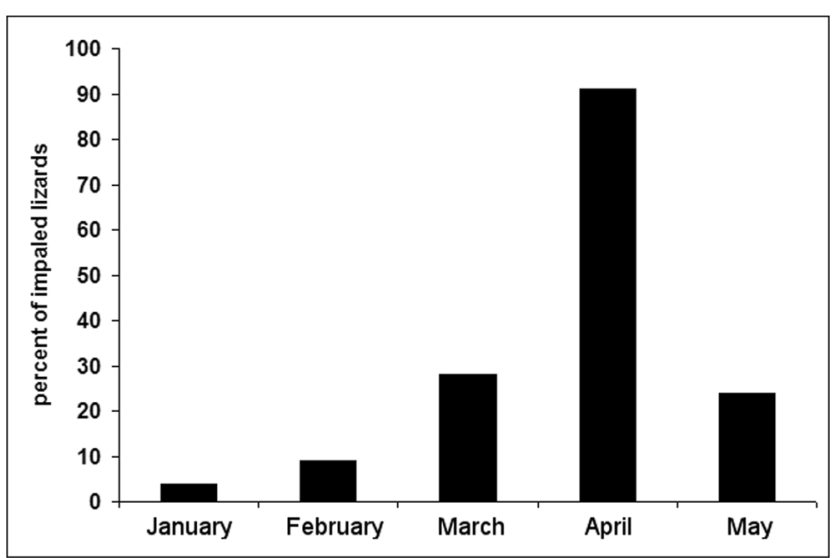

Fig. 2 Seasonal changes in numbers of impaled lizards in the great grey shrike caches. All years polled

proportion of males to females of local lizard populations living within shrike territories $(0.73: 1)$ was similar to control populations (0.8:1; Fisher exact test $F=0.21, P=0.5$; Fig. 3 ). In 2007 , the proportion of males to females in shrike territories was $(0.70: 1)$, but in controls sex ratio was reversed (2.6:1); however, the difference, due to limited sample size, was not significant (Fisher exact test $F=0.06, P=0.07$ ).

In 2006, the proportion of males to females recorded on transects was reversed in the great grey shrike territories $(0.36: 1)$ in comparison to controls $(1.4: 1$; Fisher exact test $F=0.08, P=0.10)$. In 2007, there was not such dependence; however, similar as in the previous year, the territories and the control did not differ statistically (shrike territories 0.8:1 and controls 0.6:1; Fisher exact test $F=0.41, P=0.6$ ).

However, there was a negative correlation between the number of males impaled by the great grey shrikes and the number of males in the common lizard populations recorded on transects or captured by us (Spearman rank correlation $R_{\mathrm{S}}=-0.67, P=0.048, N=21$ territories, capture and transect data as well as years combined).

\section{Discussion}

In shrikes' larders, the common lizard was much more often presented that the sand lizard. It may be caused by differences in habitats occupied by these two species (Ekner et al. 2008). Presented findings clearly indicate strong differences in predation pressure between males and females, as well as between size classes in the common lizard. In the study area, the great grey shrike predated mostly upon adults of the common lizards and the predation is male biased. This pattern, namely the dominance of males among impaled lizards, was stable in all three study years, study months and breeding territories.

The size and sex-biased predation may be caused by differences in size between age and sex classes (Le Galliard and Ferrière 2008). From a predator's perspective, the size of prey is an important trait operating in two directions; smaller classes might be not so profitable to attack. On the other hand, larger specimens might be difficult to overpower which raises the cost of transport and handling of prey. It is possible that larger individuals may represent more profitable prey, as age classes in common lizard differed significantly in body mass and body length (Ekner et al. 2008). However, such explanation does not explain the dominance of males in shrikes' larders, because in the $Z$. vivipara, females are larger than males (Roig et al. 2000). Another explanation of this size-biased predation pattern might be that smaller lizards are consumed immediately at the place of capture and are not transported or

Fig. 3 Size and sex structure of common lizard populations: impaled by great grey shrikes, populations living within shrike territories and control sites. M, adult males; F, adult females; $\mathrm{SAD}$, sub adults; J, juveniles. Data from 10 territories used for $D$ index calculations and six control populations

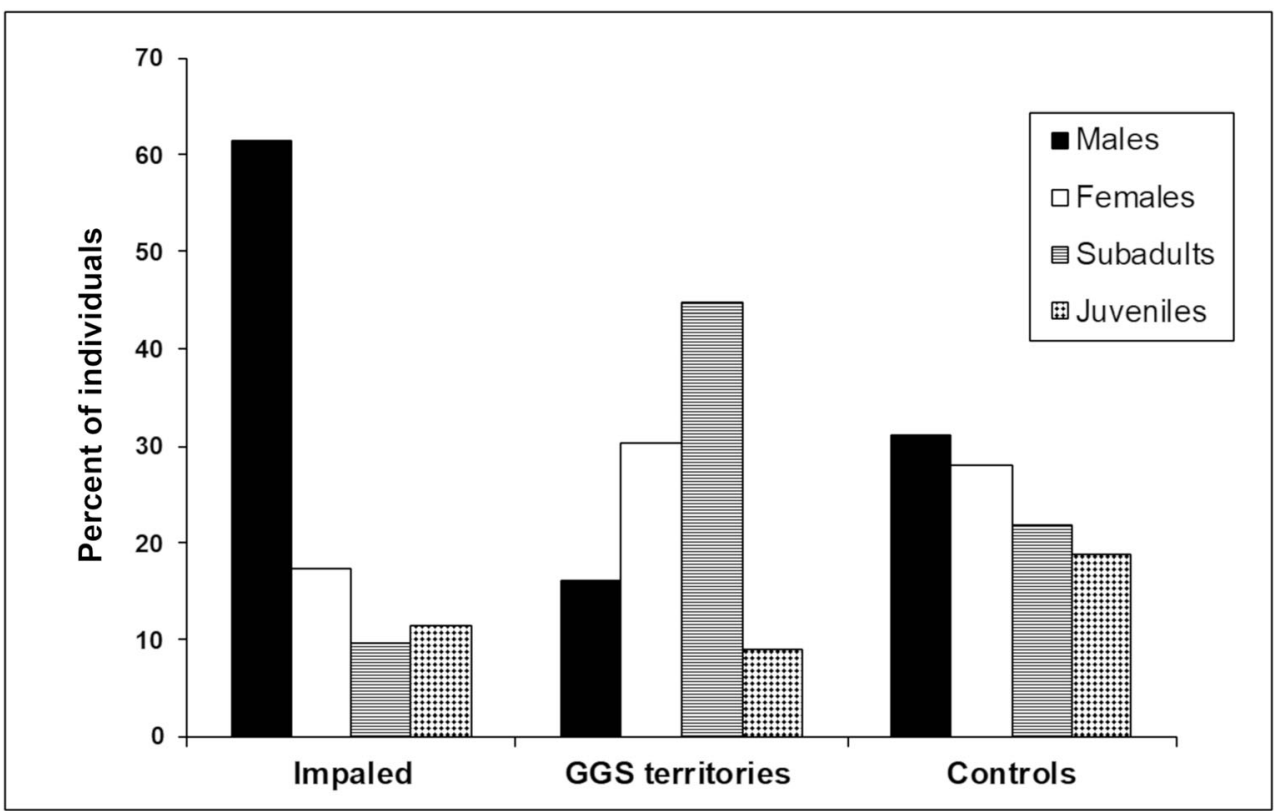


impaled and are therefore not recorded (Sonerud 1989). However, we believe this is not the case for the lizard populations in our study, as our direct observations indicate that almost all killed lizards were impaled or transported to nests or mates during courtship (Antczak et al. 2005a; Tryjanowski and Hromada 2005). Moreover, shrikes also regularly transport small insects to their butchering places or perches. In fact, consumption of lizards at the place of capture was extremely rarely observed (our unpublished data). On the other hand, females of the common lizard are slightly longer and heavier than males (Ekner et al. 2008; Le Galliard and Ferrière 2008), but this difference seems not to be a limiting factor since the great grey shrike regularly hunts much larger and heavier prey, such as small and medium size passerines, mammals or snakes (Hernandez 1995; Lorek et al. 2000; Antczak et al. 2005a).

The adult-biased predation might be underpinned by higher activity levels of adults in the reproductive season. The results show also strong male-biased predation. Several factors might be responsible for such striking differences in predation risk between sexes. Firstly, obtained data may suggest that males are exposed to predation risk significantly longer since they appeared earlier in shrike caches than females. It could be supported by earlier research, which showed that males of the common lizard are known to finish hibernation earlier than females and thus are active in field for longer (Juszczyk 1987). However, in analyses considering the period when both sexes are active in the field (since the beginning of April), dominance of males over females in the great grey shrike caches is still visible and significant.

Possible explanations for such phenomenon should consider alternative hypothesis including differences between males and females in coloration; males are much more brightly coloured than females, with orange or red underparts (personal observation) and may therefore be more visible to predators. However, for aerial predators such as shrikes, which mainly employ a sit-and-wait strategy, the coloration of breast and belly parts is largely obscured or may not be visible at all. Thus, coloration as a factor which increases the vulnerability of males to predation seems not to be a plausible explanation.

Finally, we suggest that differences in behaviour between males and females are likely to be the major determinants that influence the predation risk experienced by both sexes. Males of lacertid lizards are known to be much more active in the field and occupy larger home ranges than females (Kuranova et al. 2005). In the green lizard (Lacerta viridis), Majláth and Majlathova (2009) found strong sex and seasonal differences in activity and escape behaviour; at the beginning of reproductive season, females stayed closer to the hide and were much more vigilant than males. In other lizards, males occupied larger territories and were much more active than females, and females spent more time in refuges (Cooper 2007; Majláth and Majlathova 2009). Additional factors, in combination to activity patterns, could be anti-predator strategies displayed by both sexes. For example, males have higher running speed than females, but spend more time at a greater distance from refuges (Cooper 2007).

Sex ratio estimations showed mixed results. In the case of populations living within great grey shrike territories, females dominated over males in both transect routes and captured lizards, whereas in control populations, transects and capture data showed a more balanced sex ratio. At the same time, in shrike territories, we recorded negative correlation between number of impaled males and number of males living in lizard population. Obtained results suggested, if the number of impaled males in shrike caches reflect "local predation pressure", that shrikes might locally affect the demographic structure of the common lizard populations.

Our results suggest that important shrike-lizard interactions are not restricted only to hot or warm geographical regions and shrike predation on lizards is interesting as a general model of predator-prey interaction. The findings presented here are the latest evidence in a line of studies showing that males pay higher cost of predation in various taxa.

Acknowledgements We would like to thank M. Tobolka, A. Malecha, A. Krawczyk and $Ł$. Jankowiak for field assistance. In memory of the first author who passed away.

We are very grateful to Emma Nelson for valuable comments and language correction.

Funding information This study was supported by the Scientific Grant of the Ministry of Science of Poland No. N N 303317 433. MH was supported by grant Ministry of Education, Science, Research and Sport of the Slovak Republic ITMS26110230119.

\section{Compliance with ethical standards}

Conflict of interest The authors declare that they have no conflict of interest.

Ethical approval All applicable international, national and/or institutional guidelines for the care and use of animals were followed. All procedures performed in studies involving animals were in accordance with the ethical standards of the institution or practice at which the studies were conducted.

Open Access This article is distributed under the terms of the Creative Commons Attribution 4.0 International License (http:// creativecommons.org/licenses/by/4.0/), which permits unrestricted use, distribution, and reproduction in any medium, provided you give appropriate credit to the original author(s) and the source, provide a link to the Creative Commons license, and indicate if changes were made.

\section{References}

Antczak M, Hromada M, Grzybek J, Tryjanowski P (2004) Breeding biology of the great grey shrike in W Poland. Acta Ornithol 39:914. https://doi.org/10.3161/068.039.0105

Antczak M, Hromada M, Tryjanowski P (2005a) Spatio temporal changes in great grey shrike Lanius excubitor impaling behaviour: from 
food caching to communication signs. Ardea 93:101-107. http:// ardea.nou.nu/ardea_show_abstract.php?lang $=$ uk\&nr $=10$

Antczak M, Hromada M, Tryjanowski P (2005b) Frogs and toads in the food of the great grey shrike (Lanius excubitor): larders and skinning as two ways to consume dangerous prey. Anim Biol 55:227-233. https://doi.org/10.1163/1570756054472836

Bateman PW, Fleming PA, Wolfe AK (2017) A different kind of ecological modelling: the use of clay model organisms to explore predatorprey interactions in vertebrates. J Zool 301:251-262. https://doi.org/ 10.1111/jzo.12415

Bloomberg SP, Shine R (2000) Size-bvchbhgv predation by kookaburras (Dacelo novaeguineae) on lizards (Eulamprus tympanum: Scincidae): what determines prey vulnerability? Behav Ecol Sociobiol 48:484-489. https://doi.org/10.1007/s002650000260

Cabido C, Galan P, Lopez P, Martin J (2009) Conspicuousness-depended antypredatory behaviour may counteract coloration differences in Iberian rock lizards. Behav Ecol 20:326-370. https://doi.org/10. 1093/beheco/arn152

Campos DP, Bander LA, Raksi A, Blumstein DT (2009) Perch exposure and predation risk: a comparative study in passerines. Acta Ethol 12: 93-98. https://doi.org/10.1007/s10211-009-0061-x

Carvalho LN, Del-Claro K (2004) Effects of predation pressure on the feeding behaviour of the serpa tetra Hyphessobrycon eques (Ostariophysi, Characidae). Acta Ethol 7:89-93. https://doi.org/10. 1007/s10211-004-0093-1

Cogălniceanu D, Valdeón A, Gosá A, Al-Hemaidi AAM, Castilla AM (2015) Shrike predation on the lizard Mesalina adramitana in Qatar; a review of reported reptile and amphibian prey. Q Science Connect 1:2-8. https://doi.org/10.5339/connect.2015.1

Constanzo-Chávez J, Penna M, Labra A (2018) Comparing the antipredator behaviour of two sympatric, but not syntopic, Liolaemus lizards. Behav Process 148:34-40. https://doi.org/10.1016/j.beproc. 2018.01.005

Costantini D, Bruner E, Fanfani A, Dell'Omo G (2007) Male-biased predation of western green lizards by Eurasian kestrels. Naturwissenschaften 94:1015-1020. https://doi.org/10.1007/ s00114-007-0284-5

Cooper WEJ, Vitt LJ (1991) Influence of detectability and ability to escape on natural selection of conspicuous autonomous defenses. Can J Zool 69:757-764. https://doi.org/10.1139/z91-109

Cooper WEJ (2006a) Risk factors affecting escape behaviour in Puerto Rican Anolis lizards. Can J Zool 84:495-504. https://doi.org/10. 1139/z06-018

Cooper WEJ (2006b) Dynamic risk assessment: prey rapidly adjust flight initiation distances to changes in predator approach speed. Ethology 112:858-864. https://doi.org/10.1111/j.1439-0310.2006.01240.x

Cooper WEJ (2007) Predator number, speeds, and approach paths affect direction and flight initiation distance. J Herpetol 41:197-204. https://doi.org/10.1670/0022-1511(2007)41[197:NSAAPO]2.0. $\mathrm{CO} ; 2$

Cooper WEJ, Whiting MJ (2007) Universal optimization of flight initiation distance and habitat-driven interspecific variation in escape tactics in a Namibian lizard assemblage. Ethology 113:661-672. https://doi.org/10.1111/j.1439-0310.2007.01363.x

Ekner A, Majláth I, Majláthová V, Hromada M, Bona M, Antczak M, Bogaczyk M, Tryjanowski P (2008) Densities and morphology of two co-existing lizard species (Lacerta agilis and Zootoca vivipara) in extensively used farmland in Poland. Folia Biol-Krakow 56:5763. https://doi.org/10.3409/fb.56_3-4.165-171

Ekner A, Sajkowska Z, Dudek K, Tryjanowski P (2011) Medical cautery units as a permanent and non-invasive method of marking lizards. Acta Herpetol 6:229-236. https://doi.org/10.13128/Acta_Herpetol9346

Ekner-Grzyb A, Sajkowska Z, Dudek K, Gawelek M, Skorka P, Tryjanowski P (2013) Locomotor performance of sand lizards
(Lacerta agilis): effects of predatory pressure and parasite load. Acta Ethol 16:173-179. https://doi.org/10.1007/s10211-013-0148-2

Gabor CR, Page R (2003) Female preference for large males in sailfin mollies, Poecilia latipinna: the importance of predation pressure and reproductive status. Acta Ethol 6:7-12. https://doi.org/10.1007/ s10211-003-0081-x

Gallagher AJ, Lawrence MJ, Jain-Schlaepfer SMR, Wilson ADM, Cooke SJ (2016) Avian predators transmit fear along the air-water interface influencing prey and their parental care. Can J Zool 94:863-870. https://doi.org/10.1139/cjz-2016-0164

Gazzola A, Balestrieri A, Ghitti M, Paganelli D, Galeotti P (2017) Behavioural and life history responses to predation risk by common frog tadpoles exposed to two predators during ontogeny. Acta Ethol 20:235-241. https://doi.org/10.1007/s10211-017-0266-3

Grange S, Barnier F, Duncan P, Gaillard JM, Valeix M, Ncube H, Périquet S, Fritz H (2015) Demography of plains zebras (Equus quagga) under heavy predation. Popul Ecol 57:201-214. https://doi.org/10. 1007/s10144-014-0469-7

Hasegawa M (1990) The thrush Turdus celaenops, as an avian predator of juvenile Eumeces okadae on Mayake-Jima, Izu Islands. Jpn J Herpetol 13:65-69. https://doi.org/10.5358/hsj1972.13.3 65

Hawlena D, Perez-Mellado V (2009) Change your diet or die: predator induced shifts in insectivorous lizard ecology. Oecologia 161:411419. https://doi.org/10.1007/s00442-009-1375-0

Hawlena D, Saltz D, Abramsky Z, Bouskila A (2010) Ecological trap for desert lizards caused by anthropogenic changes in habitat structure that favor predator activity. Conserv Biol 24:803-809. https://doi. $\operatorname{org} / 10.1111 / \mathrm{j} .1523-1739.2010 .01477 . x$

Hayward MW, Lyngdoh S, Habib B (2014) Diet and prey preferences of dholes (Cuon alpinus): dietary competition within Asia's apex predator guild. J Zool 294:255-266. https://doi.org/10.1111/jzo.12171

Hernandez A (1995) Temporal - spatial patterns of food caching in two sympatric shrike species. Condor 97:1002-1010. https://doi.org/10. 2307/1369539

Hoy SR, Petty SJ, Millon A, Whitfield DP, Marquiss M, Davison M, Lambin X (2015) Age and sex-selective predation moderate the overall impact of predators. J Anim Ecol 84:692-701. https://doi. org/10.1111/1365-2656.12310

Hromada M, Kuczyński L, Kristin A, Tryjanowski P (2003) Animals of different phenotype differentially utilize dietary niche - the case of the great Grey shrike Lanius excubitor. Ornis Fenn 80:71-78. https://lintulehti.birdlife.fi/\#/pdfhakucrit . Accessed November 2018

Hromada M, Antczak M, Valone TJ, Tryjanowski P (2008) Settling decisions and heterospecific social information use in shrikes. PLoS One 3:e3930. https://doi.org/10.1371/journal.pone.0003930

Jacobs J (1974) Quantitative measurement of food selection. Oecologia 14:413-417. https://doi.org/10.1007/bf00384581

Juszczyk W (1987) Amphibians and reptiles of Poland. PWN, Warsaw (Translated from Polish)

Kuranova VN, Patrakov SV, Bulakhova NA, Krechetova OA (2005) The study of the ecological niche segregation for sympatric species of lizards Lacerta agilis and Zootoca vivipara. In: Ananjeva N, Tsinenko O (eds) Herpetologia Petropolitana. Saint-Petersburg, Russia, pp 171-175

Lefranc N, Norfolk T (1997) Shrikes. A guide to the shrikes of the World. Pica Press, Sussex

Le Galliard JF, Ferrière R (2008) Evolution of maximal endurance capacity: natural and sexual selection across age classes in a lizard. Evol Ecol Res 10:157-176. http://www.evolutionary-ecology.com/ abstracts/v10/2246.html

Lepley M, Thevonot M, Guiilaume CP, Ponel P, Bayle P (2004) Diet of nominate southern Grey shrike Lanius meridionalis meridionalis in the north of its range (Mediterranean France). Bird Study 51:156 162. https://doi.org/10.1080/00063650409461347 
Lima SL (1998) Nonlethal effects in the ecology of predator- prey interaction. What are the ecological effects of anti- predator decisionmaking? BioScience 48:25-34. https://doi.org/10.2307/1313225

Lima SL, Dill LM (1990) Behavioral decisions made under the risk of predation: a review and prospectus. Can J Zool 68:619-640. https:// doi.org/10.1139/z90-092

Lorek G, Tryjanowski P, Lorek J (2000) Birds as prey of the great Grey shrike (Lanius excubitor). Ring 22:37-44. http://www.wbwp-fund. eu/ring/ . Accessed November 2018

Majláth I, Majlathova V (2009) Escape behavior of green lizard (Lacera viridis) in Slovak karst. Acta Ethol 12:99-103. https://doi.org/10. 1007/s10211-009-0063-8

Manganaro A, Salvati L, Ranazzi L, Fattorini S (1999) Predation on geckos (Gekkonidae) by urban tawny owls (Strix aluco). Avocetta 23:73-75 http://ciso-coi.it/avocetta/archivio-pubblicazioni/ avocetta-volume-23-n-1-2-1999

Marescot L, Forrester TD, Casady DS, Wittmer HU (2015) Using multistate capture-mark-recapture models to quantify effects of predation on age-specific survival and population growth in black-tailed deer. Popul Ecol 57:185-197. https://doi.org/10.1007/s10144-0140456-z

Martin J (2001) When hiding from predators is costly: optimization of refuge use in lizards. Etologia 9:9-13 http://www.etologia.org

Martín J, López P (1990) Amphibians and reptiles as prey of birds in southwestern Europe. Smithson Herpetol Infor Serv, 82nd edn. https://repository.si.edu/bitstream/handle/10088/32676/SHIS_82.pdf

Martin J, López P (1995) Influence of habitat structure on the escape tactics of the lizard Psammodramus algirus. Can J Zool 73:129 132. https://doi.org/10.1139/z95-014

Martín J, López P (1996) Avian predation on a large lizard (Lacerta lepida) found at low population densities in Mediterranean habitats: an analysis of bird diets. Copeia 1996:722-726. https://doi.org/10. $2307 / 1447538$

Marshall KLA, Philpot KE, Stevens M (2015) Conspicuous male coloration impairs survival against avian predators in Aegean wall lizards, Podarcis erhardii. Ecol Evol 5:4115-4131. https://doi.org/10. $1002 /$ ece 3.1650

McLaughlin JF, Roughgarden J (1989) Avian predation on Anolis lizards in the northeastern Caribbean: an interisland contrast. Ecology 70: 617-628. https://doi.org/10.2307/1940213

Morelli F, Bussière R, Goławski A, Tryjanowski P, Yosef R (2015) Saving the best for last: differential usage of impaled prey by redbacked shrike (Lanius collurio) during the breeding season. Behav Process 119:6-13. https://doi.org/10.1016/j.beproc.2015.07.006

Moyaho A, Garcia CM, Manjarrez J (2004) Predation risk is associated with the geographic variation of a sexually selected trait in a viviparous fish (Xenotoca variata). J Zool 262:265-270. https://doi.org/ 10.1017/S095283690300459X

Padilla DP, Nogales M, Pérez AJ (2005) Seasonal diet of an insular endemic population of southern Grey shrike Lanius meridionalis koenigi on Tenerife, Canary Islands. Ornis Fenn 82:155-165. https://lintulehti.birdlife.fi/\#/pdfhakucrit

Padilla DP, Nogales M, Merrero P (2007) Prey size selection of insular lizards by two sympatric predatory bird species. Acta Ornithol 42: 167-172. https://doi.org/10.3161/068.042.0211

Padilla DP, Nogales M (2009) Behaviour of kestrels feeding on frugivorous lizards: implications for secondary seed dispersal. Behav Ecol 20:872-877. https://doi.org/10.1093/beheco/arp075

Padilla DP, González-Castro A, Nieves C, Nogales M (2009) Trophic ecology of the southern Grey shrike (Lanius meridionalis) in insular environments: the influence of altitude and seasonality. J Ornithol 150:557-568. https://doi.org/10.1007/s10336-009-0381-7

Pellitteri-Rosa D, Bellati A, Cocca W, Gazzola A, Martín J, Fasola M (2017) Urbanization affects refuge use and habituation to predators in a polymorphic lizard. Anim Behav 123:359-367. https://doi.org/ 10.1016/j.anbehav.2016.11.016
Pruitt JN, Howell KA, Gladney SJ, Yang Y, Lichtenstein JLL, Spicer ME, Echeverri SA, Pinter-Wollman N (2017) Behavioral Hypervolumes of predator groups and predator-predator interactions shape prey survival rates and selection on prey behavior. Am Nat 189:254 266. https://doi.org/10.1086/690292

Roig JM, Carretero MA, Llorente GA (2000) Reproductive cycle in a Pyrenean oviparous population of the common lizard (Zootoca vivipara). Neth J Zool 50:15-27. https://doi.org/10.1163/ 156854200505775

Sheriff MJ, McMahon EK, Krebs CJ, Boonstra R (2015) Predatorinduced maternal stress and population demography in snowshoe hares: the more severe the risk, the longer the generational effect. J Zool 296:305-310. https://doi.org/10.1111/jzo.12249

Sonerud GA (1989) Allocation of prey between self-consumption and transport in two different sized central place foragers. Ornis Scand 20:69-71. https://doi.org/10.2307/3676711

Stapley J (2004) Do mountain log skinks (Pseudemoia entrecasteauxii) modify their behaviour in the presence of two predators. Behav Ecol Sociobiol 56:185-189. https://doi.org/10.1007/s00265-004-0771-z

Stamps JA (1984) Rank-dependent compromises between growth and predator protection in lizard (Anolis aeneus) dominance hierarchies. Anim Behav 32:1101-1107. https://doi.org/10.1016/S00033472(84)80226-2

Steen R, Low LM, Sonerud M (2011) Delivery of common lizards (Zootoca (Lacerta) vivipara) to nests of Euroasian kestrels (Falco tinnunculus) determined by solar height and ambient temperature. Can J Zool 89:199-205. https://doi.org/10.1139/Z10-109

Strauss RE (1979) Reliability estimates of Ivlev's electivity index, the forage ratio, and a proposed linear index of food selection. Trans Am Fish Soc 111:517-522. https://doi.org/10.1577/15488659(1979)108<344:REFIEI $>2.0$. CO;2

Surmacki A, Ożarowska-Nowicka A, Rosin Z (2013) Color polymorphism in land snail Cepaea nemoralis (Pulmonata:Helicidae) as viewed by potential avian predators. Naturwissenschaften 100: 533-540. https://doi.org/10.1007/s00114-013-1049-y

Thaker M, Lima SL, Hews DK (2009) Alternative antipredator tactics in tree lizard morphs: hormonal and behavioural responses to a predator encounter. Anim Behav 77:395-401. https://doi.org/10.1016/j. anbehav.2008.10.014

Tryjanowaki P, Hromada M, Antczak M (1999) Breeding habitat slection in the great gray shrike Lanius excubitor - the importance of meadows and spring crops. Acta Ornithol 34:59-63. http://rcin. org.pl/dlibra/docmetadata?id=45201\&from=publication

Tryjanowski P, Hromada M (2005) Do males of the great grey shrike, Lanius excubitor, trade food for extrapair copulations? Anim Behav 69:529-533. https://doi.org/10.1016/j.anbehav.2004.06.009

York JR, Baird TA (2016) Juvenile collared lizards adjust tail display frequency in response to variable predatory threat. Ethology 122: 37-44. https://doi.org/10.1111/eth.12442

Yosef R, Pinshow B (1989) Cache size in shrikes influences female mate choice and reproductive success. Auk 106:418-421. http://www. jstor.org/stable/4087861

Yosef R, Pinshow B (2005) Impaling in true shrikes (Laniidae): a behavioural and ontogenetic perspective. Behav Proc 69:363-369. https:// doi.org/10.1016/j.beproc.2005.02.023

Yosef R, Sharpe CJ, Marks JS, Kirwan GM (2018) Great Grey shrike (Lanius excubitor). In: del Hoyo J, Elliott A, Sargatal J, Christie DA, de Juana E (eds) handbook of the birds of the world alive. Lynx edn, Barcelona. https://www.hbw.com/node/60482

Zar JH (1999) Biostatistical analysis, 4th edn. Prentice Hall, New Yersey

Publisher's note Springer Nature remains neutral with regard to jurisdictional claims in published maps and institutional affiliations. 